sciendo

\title{
Quine and the Contemporary Debate on Mindreading
}

\author{
Giancarlo Zanet \\ University of Palermo
}

Disputatio Vol. 4, No. 32

May 2012

DOI: 10.2478/disp-2012-0006

ISSN: 0873-626X 


\title{
Quine and the Contemporary Debate on Mindreading
}

\author{
Giancarlo Zanet \\ University of Palermo
}

BIBLID [0873-626X (2012) 32; pp. 395-412]

\begin{abstract}
The paper examines some of the questions emerging from the debate on mindreading regarding Quine's legacy and contribution to a new agenda on the issue. Since mindreading is an exercise in folk-psychology, a) which role folk psychology has to play according to Quine? b) was Quine's account of mindreading closer to theory-theory, simulation theory or hybrid theory? c) was Quine a rationality theorist? d) are hybrid-theory and rationality theory incompatible as many would suggest? On the score of the answers to these questions, the paper tries to suggest a Quinean inspired blend of rationality-based and hybrid view-based strategies to explain mindreading.
\end{abstract}

\section{Keywords}

Mindreading, Simulation Theory, Empathy, Folk-psychology, Rationality.

Quine and mindreading: is it an oxymoron?*

How do we understand people? One answer is that we mindread. What is mindreading? Roughly, mindreading is the skill of understanding a subject, explaining and/or predicting her thoughts and actions. We manage this task attributing to our target a mind, where this means ascribing to the target mental states of various kind like per-

* In developing the ideas presented in this paper I benefited from discussions and criticisms by many people. I would like to thank Francesca Di Lorenzo Ajello, Franco Lo Piparo, Christopher Hookway, Lucia Pizzo Russo, Sebastiano Vecchio, Paolo Virno, Antonio Rainone, Francesca Piazza, Patrizia Laspia, Marco Carapezza, Marco Mazzone, Francesco La Mantia, Gianluigi Oliveri, Claudia Rosciglione and Giuseppe Vicari. I would also like to thank the organizing committee of the Word and Object, 50 Years Later conference, especially Francesca Ervas and Vera Tripodi, and the audience of the conference for helpful questions and comments.

Disputatio, Vol. IV, No. 32, May 2012 
ceptions, beliefs, desires, intentions, emotions. It sounds almost obvious that explaining and predicting behavior are capacities essential to human meaningful interactions, to human cognitive and social life.

Given this definition, it might seem difficult to see what could be the relationship between Quine «the behaviorist» and mindreading. Isn't Quine, just the Quine of Word and Object, the strongest opponent of every form of mentalism? Isn't Quine the strongest opponent of any ontological commitment to intentional states? That prima facie oddity, I hope, is going to become less strident in what follows.

The questions that emerge about Quine from the debate on mindreading are many. Since mindreading is an exercise in folkpsychology, a) which role folk psychology has to play according to Quine? b) was Quine's account of mindreading closer to theorytheory, simulation theory or hybrid theory? c) was Quine a rationality theorist? d) are hybrid-theory and rationality theory incompatible as Nichols and Stich (Nichols and Stich 2003) or Goldman (2006) would suggest?

On the score of the answers to these questions, the paper tries to suggest a Quinean inspired blend of rationality-based and hybrid viewbased strategies to explain mindreading.

In the second section, the main features of the contemporary debate on mindreading are presented. The debate is understood as featuring, in the end, two main mutually exclusive options: hybridtheory and rationality-theory. In the third section, answers to questions a) and b) are offered. Quine's argument for the indispensability of folk-psychology is reconstructed and his account of mindreading is analyzed and identified as a version of hybrid-theory in which simulation plays a major role. Quine's effort, within the framework of his naturalized epistemology, in offering a unified account of our understanding of world and other people through an examination of perception is considered as a first relevant legacy to the contemporary debate on mindreading. It suggests a way of claiming that there is no sharp divide between knowledge of the world and knowledge of the other minds and overcoming the traditional distinction between natural and social science.

In the fourth section, answers to questions c) and d) are sketched. A way to find a reconciliation between rationality and simulation is explored through a brief comparison between Davidson and Quine. It is meant to argue for the idea that the Quinean inspired hybrid theory 
based on empathy does not exclude the use of normative notions and the appeal to rationality. This is identified as a second relevant legacy to the contemporary debate. Taken together, the two legacies mentioned above could constitute an interesting agenda for the future debate.

\section{The contemporary debate on mindreading: a very brief introduction}

When we ask how we do achieve the complex ability or skill to mindread, we find that the contemporary debate features, at least, three different theoretical options: theory-theory of mind, simulation theory, and rationality theory.

Each one comes in different sub-varieties. There are at least two versions of theory -theory: the child scientist theory (Gopnik and Meltzoff 1997; Gopnik, Meltzoff and Kuhl 1999) and the modularity theory (Fodor 1987; Leslie 1987, 1988, 1994; Baron-Cohen 1995). According to the theory-theory view on mindreading when you perform mindreading tasks you use a theory of mind. We have «a rich body of mentally represented information about the mind, and $[\ldots]$ this information plays a central role in guiding the mental mechanisms that generate our attributions, predictions, and explanations.» (Stich and Nichols 2003, 239). The two versions mainly differ in their answer to the developmental question: how do we arrive to achieve the complex skill of mindreading? Is it innate and modular? Or does it evolve from childhood to adulthood through radical changes?

There are also many versions of simulation theory. The core idea is that when performing a mind reading task you use a simulation routine consisting «in putting yourself in the target's shoes». You don't need any kind of theory-like knowledge, you need just the ability to project yourself on the target, to engage in a sort of «pretend play» and, using your own belief-formation, desire-formation and decision-making mechanisms, to see what comes out. The outcome of the simulation process counts as the mental state you will predict to be that of your target, or you will use to explain its behavior. Among the simulationists, Goldman (2006), Gordon (1986, 1995, 2005), and Gallese (Gallese 2001; Gallese, Keysers, and Rizzolatti 2004) differentiate themselves about the extent to which we can say we are using simulation, about the extent of mirroring 
processes in simulation, and, above all, about the role of introspection in mind reading. A different perspective on simulation is advocated by Jane Heal (2003), because her approach is characterized by the tendency to be conducted in a less empirical and more a priori fashion and by the idea that simulation is supported by rationality.

Notwithstanding these differences between theory-theory and simulation theory, it is almost becoming a shared view that a good account of mindreading can be afforded by a hybrid view, a blend of theory-theory and simulation (Botterill and Carruthers 1999; Stich and Nichols 2003, Nichols and Stich 2003; Goldman 2006). People who agree on hybrid view have different accounts of the exact step in the mindreading process where the hybridization takes place. They have also different accounts of which one of the different mindreading abilities is subserved by simulation or theory.

Stich and Nichols (2003, Nichols and Stich 2003) claim that inference prediction is a mindreading skill subserved by simulation, and that desire-attribution and discrepant belief-attribution are mindreading skills that cannot be explained by simulation, but need theory-like generalization.

Goldman distinguishes between two levels of mindreading: lowlevel and high-level. He claims that the low-level mindreading skills, like emotions recognition, are simulation processes caused by mirroring processes, even though mirroring does not exhaust mindreading. Goldman claims that there is a high-level mindreading in which we simulate without mirroring. It could be implemented by theory (Goldman 2006: 43-46), because it is a kind of simulation in which previous experience, knowledge and memory play a major role (Goldman 2009).

If we follow this trend, we might say that just two different options are left on the field: hybrid view and rationality theory (also called interpretativism). The core idea of rationality theory, shared by Davidson (Davidson 1984, 2004) and Dennett (Dennett 1987), is that mindreading someone is to treat her as rational, namely to attribute her mental states such that she comes out as a rational thinker and agent. In his book The Intentional Stance, Dennett states:

However rational we are, it is the myth of our rational agenthood that structures and organizes our attributions of belief and desire to others and that regulates our own deliberations and investigations. We aspire to rationality, and without the myth of our rationality the concepts of 
belief and desire would be uprooted. Folk psychology, then, is idealized in that it produces its predictions and explanations by calculating in a normative system; it predicts what we will believe, desire, and do, by determining what we ought to believe, desire, and do. (Dennett 1987: 52)

According to Goldman (2006: Chapter 3), rationality theory does not provide a plausible account of mindreading and it is not compatible with a simulationist account. One of the criticisms offered by Goldman is that we cannot find the kind of rationality imagined by rationality theorist in actual agents and thinkers. Goldman's argument are not new. They are supported by the psychological studies on the failure of rationality by Kaheneman, Tversky and others (Kahnerman, Slovic, Tvershy 1982). ${ }^{1}$

Curiously enough, both theorists like Goldman and rationality theorists refer to Quine as a predecessor. ${ }^{2}$ Goldman himself underlines places in Quine's works where he assumes a simulationist stance, but he declares that, even if Quine can be viewed as a simulationist, no influence of his thought can be traced back in simulationist theorists like himself, Gordon and Heal (Goldman 2006: 18). ${ }^{3}$ The influence of Quine on rationality theorists is quite direct and well known. Davidson and Dennett both assume the so called principle of charity, evoked by Quine (1960:59), as the key rule to interpret others and attribute them propositional attitudes.

\footnotetext{
${ }^{1}$ The negative results of these inquiries and their consequences for rationality theories have been elucidated and discussed in Thagard and Nisbett (1983) and Stich (1983, 1985, 1990). Dennett's answer to this objections is that psychological experiments deliberately provoking irrational responses induce a "pathology" (Dennett 1987: 52) in a system that, even tough is not perfect, is still "pretty" rational (Dennett 1987: 50).

${ }^{2}$ This double aspect of Quine's account have been well noticed by Stich (1983; 1985) and Dennett (1987).

${ }^{3}$ This assumption is problematic. Goldman, in fact, quotes Quine's passages about projecting strategy from Word and Object in his seminal paper on simulation (Goldman 1989)
} 
Perception, folk-psychology and simulation based hybridtheory

Quine casts many doubts about propositional attitudes and intentionality in general. In Chapter VI of Word and Object, emphatically titled Flight from intension, in the crucial section 45 titled The Double Standard, Quine recognizes, with Chisholm and Brentano, that the intentional vocabulary is not reducible, because «there is no breaking out of the intentional vocabulary by explaining its members in other terms» (Quine 1960: 220). That irreducibility brings as a consequence a refusal of «an autonomous science of intention (Quine 1960: 221).

As Quine points out in Word and Object (Quine 1960: 219) and in more recent writings, if we look at the idiom of propositional attitudes from the austere ontological point of view of science, we face many troubles when we try to include it in our «literal and austere formulation of one's theory of the world» (Quine 1989: 351).

Nonetheless, we don't need to refuse or eliminate the intentional idiom. ${ }^{4}$ In the same section of Word and Object Quine opens the way to a different option declaring that he would not «foreswear daily use of intentional idioms, or maintain that they are practically dispensable» (Quine 1960: 221). In fact, Quine claims that the intentional idiom, exemplified by indirect quotation, is not «humanly dispensable» (Quine 1960: 218). And he sketches the psychological mechanism underlying it that we commonly use: «we project ourselves into what [...] we imagine the speaker's state of mind to have been»; we perform «an essentially dramatic act» through which we can «find ourselves attributing beliefs, wishes, and strivings even to creatures lacking the power of speech, such is our dramatic virtuosity» (Quine 1960: 219).

\footnotetext{
${ }^{4}$ Quine's attitude is, in this respect, different from eliminastivist's project in philosophy of mind. Eliminativists like Churchland (1989) claim that folkpsychology has to be dismissed as a bankruptcy enterprise in favor of scientific psychology. Scientific psychology must replace to some extent our common sense psychology even in every day usage. Quine's principle of ontological austerity may support such a view. But Quine himself never draws similar consequences from his attitude towards folk-psychology. Quite the contrary, he increasingly during the decades remarks its role in his account of mind and language.
} 
Here we can find a first sketch of the structure of that psychological phenomenon Quine, later, would have called «empathy». What is empathy according to Quine? It is the ability of a subject to project itself on mental states of a target, where projecting means the ability of simulating, through imagination, in its own mind the target's mental states.

Even though Quine's reflections on the subject are present as a topic in his earlier works, ${ }^{5}$ a more detailed account and the very use of the notion of empathy are to be found in his latest books: Pursuit of Truth (1992, Chapters III and IV) and From Stimulus To Science (1995, Chapter VIII). Developing the idea that the intentional idiom is not «humanly dispensable», Quine claims that the command of mentalistic notion such as 'x perceives that $\mathrm{p}$ ' seems to be «as old as language» (Quine 1992: 61) and that «the handing down of language is implemented by a continuing command, tacit at least, of the idiom ' $x$ perceives that $\mathrm{p}^{\prime} \gg$. Mentalistic idiom intrudes already at the level of observation sentences, determining an early bifurcation of physicalistic and mentalistic talk. The bifurcation reminds us that «man is a forked animal» (Quine 1992: 62), in Quine's phrase.

If the learning of language is implemented by the «virtual if not literal» mastery of mentalistic idiom (Quine 1992: 61), then it is not surprising that Quine, in From Stimulus To Science, claims that the «perception of another's unspoken thought» by means of instinctive empathy is «older than language» (Quine 1995: 89). A confirm of that comes, continues Quine, from child psychology: «an infant of just a few days old responds to an adult's facial expression, even to imitating it by the unlearned flexing of appropriate muscles» (Quine 1995: 89). ${ }^{6}$

\footnotetext{
${ }^{5}$ It is worth noticing that the idea that the ability to project oneself in the place of another has to play a crucial role in translation does not appear for the first time in Pursuit of Truth. It can be found in Word and Object and traced back to The Problem of Meaning in Linguistics (Quine 1953) where we can read: «But, as the sentences undergoing translation get further and further from mere reports of common observations, the clarity of any possible conflict decreases; the lexicographer comes to depend increasingly on a projection of himself, with his Indo-European Weltanschauung, into the sandals of his Kalaba informant. He comes also to turn increasingly to that last refuge of all scientists, the appeal to internal simplicity of his growing system» (Quine 1953: 63).

${ }^{6}$ Quine should be referring to the pioneeristic experiments described in Meltzoff and Moore 1977.
} 
The explanation for this phenomenon is the instinct of empathy ${ }^{7}$. It works in our ascription of perceptions, for «we all have - Quine writes - an uncanny knack for empathizing another's perceptual situation, however ignorant of the physiological or optical mechanism of his perception» (Quine 1992: 42).

Empathy is a pervasive phenomenon and - as Quine remarks - it «guides the linguist still as he rises above observation sentences through his analytical hypotheses, though there he is trying to project into the native's associations and grammatical trends rather than his perceptions. And much the same must be true of the growing child» (Quine 1992: 43). ${ }^{8}$

In ascribing to a target that 'Tom perceives that $\mathrm{x}$ ' we rely on the ability to detect his mental state «by the empathetic observation of the subject's facial expression and what is happening in front of him» (Quine 1992: 62). This ability plays a crucial role both in the field linguist case, for he «empathizes the native's perception that a rabbit has appeared» (Quine 1992: 62) and in the case of the child language learning from his parents. In the latter case, empathy plays a role both in child and adult. The child «does not just hear the sentence, see the reported object or event, and then associate the two. He also notes the speaker's orientation, gesture, and facial expression. In his as yet inarticulate way he perceives that the speaker perceives the object and event» (Quine 1995: 89).

The child needs to read, even though in a way, probably not entirely conscious and not even articulated in a theoretical fashion, what the adult has in mind. This is also true of the adult who, to give his assent to child's utterance, takes note of his orientation and facial expression because what he is interested in it is not the «mere truth of the utterance» but the fact that «the child has to have perceived its truth» (Quine 1995: 89).

It seems that, according to Quine, what the adult has to evaluate is not mere correspondence between world and word, but the fact that the correspondence is epistemically established in a reliable way, the fact that the adult can make a plausible psychological assumption about the child's state of mind.

\footnotetext{
${ }^{7}$ See Rainone $(2005,2010)$ for a discussion of the role of empathy in Quine.

${ }^{8}$ See note 5 .
} 
The same mechanism is at play when we try to figure out what Tom is thinking. Quine treats this case like an extension of perception's cases. When we say 'Tom perceives that the train is late', we have two ways to understand what Tom is perceiving. Tom can tell us about it or we can observe Tom's behavior. He walks impatiently, looks at the clock, looks along the track.

Then, according to Quine, «along with acquiring such habits ourselves, we have learned to observe similar manifestations on the part of others. We are ready to see our own ways replicated in another person» (Quine 1995: 63). In the same way as in child case, our ascription is based on "projecting [...] into Tom 's situation and Tom's behavior pattern, and finds thereby that the sentence 'The train is late' is what comes naturally» (Quine 1995: 63).

As we move away from observation sentences, notes Quine, «ascription of perceptions call increasingly for background knowledge and conjecture on the ascriptor's part» (Quine 1992: 64). This is indeed the case of ascriptions of beliefs. When we ascribe belief our evidence is similar to that of when we ascribe perceptions but is «usually more tenuous» (Quine 1992: 66). For this reason in ascribing we need to «reflect on the believer's behavior, verbal or otherwise», take into account «what we know of his past», and «conjecture that we in his place would feel prepared to assent, overtly or covertly, to the content clause» (Quine 1992: 66).

Generalizing the case of belief's ascription, Quine remarks that «empathy is why we ascribe a propositional attitude by a content clause» that is supposed «to reflect the subject's state of mind rather the state of things». So we can say that «the quotational account reflects the empathy that invests the idioms of propositional attitudes from 'perceives that' onward» (Quine 1992: 68-69).

The conclusion of this line of argument, from an ontological point of view, is related with Quine's endorsement of anomalous monism. According to that doctrine «there is no mental substance, but there are irreducibly mental ways of grouping physical states and events» (Quine 1992: 72). Mental predicates interacting one with another engendered «age-old strategies for predicting and explaining human action», namely folk-psychology. So they «complement natural science in their incommensurable way, and are indispensable both to the social sciences and to our everyday dealings» (Quine 1992: 7273). 
Let me now summarize and schematize the main features of Quine's account of mindreading.

Quine recognizes that folk-psychology is indispensable to our mutual understanding. He is inclined to treat it as a «practical» competence (Quine 1992: 46). Its «method» is empathy (Quine 1992: 46). Under the label 'empathy' he subsumes many cognitive skills that precede language. They can be consciously (i.e. in the field linguists case) or unconsciously exercised (i.e. in the learning language child case and in the case of many adults' everyday dealings). These skills are: a) imitation; b) detection of face expression, orientation, gesture; c) joint attention; d) pretense/imagination. All of these are operating in attribution of perceptions which makes possible and support communication and language learning. Quine is inclined to think that 'perceive that' followed by an observation sentence is «the primeval idiom for ascribing a thought» (Quine 1995: 90). We have two ways to get the «perception of another's unspoken thought» (Quine 1995: 89), i.e. mindreading: a) behavior and b) language. If A tries to understand what $\mathrm{B}$ has in mind observing her behavior, A's activity has the following structure: i.) seeing A's ways «replicated» in B's ways, i.e. recognizing similarities between A's behavior and B's behavior; ii.) hypothesizing that B's mind is «pretty much like» A's own mind (Quine 1992: 46); iii.) projecting A on B's shoes; iv.) simulating B's situation and behavior; v.) seeing «what comes naturally» (Quine 1992: 63).

The same structure holds when A tries to ascribe to B a belief. The crucial difference is that in belief-attribution case the evidence on which A bases her attribution is weaker. A's reflections and conjectures and her knowledge of B's background and past become more and more relevant. Moreover, in belief-attribution, the «easiest way of determining» B's belief is «asking» her (Quine 1992: 66) and listening and understanding the «arguments offered in support of a belief» (Quine 1992: 67) by B. This obviously implies the use of language.

As far as I can see we are facing again solutions the core of which was already present in Word and Object, even though they have been growing more explicit in recent years. Quine recognizes the indispensability of mentalistic idiom and identifies in projection, replication and simulation, in one word, empathy, the strategies we use in mindreading. 
The analysis of Quine's account of mindreading, in this section, is meant to give an answer to some of the questions raised in the first section. It gives an answer to question a) about the role of folkpsychology. What should be remarked is the relevance of what we might call the indispensability argument: folk-psychology cannot be eliminated. Moreover, it seems that it should be intended mainly as a practical form of knowledge, as simulationist would suggest, and not, strictly speaking, as a theoretical one.

It gives also an answer to question b) about Quine and the theorytheory versus simulation theory debate. Which option is he defending? In general, we could say that he is quite near to the hybrid theory, a blend of theory-theory and simulation in which simulation plays a prominent role. It is clear, even from the reconstruction of Quine's thoughts on the topic presented here, that he does not give an in depth treatment of the various notions he uses. Readers well acquainted with the contemporary debate on mindreading and social cognition can easily see that each of the notions has had a detailed treatment in the neuroscientific, psychological and philosophical literature of the last three decades. ${ }^{9}$ Quine envisages a way of putting them together, of seeing their relationship, of understanding how they can be integrated in a naturalized epistemology ${ }^{10}$. In fact, Quine's interest on mindreading is part and parcel of his effort to answer the crucial question of naturalized epistemology: «how we, physical denizens of the physical world, can have projected our scientific theory of that whole world from our meager contacts with it» (Quine 1995: 16). He is trying to find a unified account of our understanding of the world and other people through an examination of

\footnotetext{
${ }^{9}$ In my reconstruction (third section) I have enlisted four skills for empathy in Quine's account: a) imitation ; b) detection of face expression, orientation, gesture; c) joint attention; d) pretense/imagination. Excellent studies on imitation are included in two volumes edited by Hurley and Chater (2005). On joint attention valuable contributes are included in Elian et al. (2005). On pretence and imagination see Nichols and Stich (2003) and Currie and Ravenscroft (2002). For an overview on these issues and their interconnections from a neuroscientific point of view see Blackmore and Frith (2003). The various aspects of simulation routine (replication, like me, projecting, simulating) have been studied by the simulationist theorists I have been quoting in the paper. They play also a crucial role in developmental psychology: Meltzoff (2009), Tomasello (1999).

${ }^{10}$ For an introduction to Quine's naturalized epistemology and its historical roots see Zanet (2007).
} 
perception ${ }^{11}$. As far as I can see, he is inclined to think that there is no sharp divide between knowledge of the world and knowledge of the other minds, as the traditional distinction between natural and social science would suggest. This is his first relevant legacy to the contemporary debate on mindreading.

\section{Empathy and rationality}

The second legacy consists in a suggestion that needs to be developed about the way to find a reconciliation between rationality and simulation. What follows amounts also as an answer to questions c) and d) in the first section.

Quine seems to suggest there are differences among various mental states' ascriptions and these are differences in degree of the background knowledge involved. Ascription of perception is the most basic, in a double sense. It is the first one we, when we are children, exercise and it has a deep influence on our language learning. It is the one that calls less for background knowledge and information. To ascribe perceptions we need some relevant cognitive skills and exercise empathy. Beliefs ascription and thoughts ascription call for a different degree of use of background knowledge and of conjectures. The more we want to be successful in ascribing beliefs, the more we need to take into account believer's behavior and background knowledge. But one may ask what happens when we do not have such a knowledge. This is pretty the case of the linguist in the jungle and, at least in a certain sense, the case of the adult trying to understand a child. In such cases we try to project ourselves starting from our common practical knowledge of human psychology. This last consideration brings us to a crucial point. A way of recasting rationality versus simulation debate within Quine's philosophy is reflecting on the prima facie tension between the principle of charity and empathy. That tension comes to the fore when we look to Quine-Davidson debate about the issue.

It is well known that Davidson endorses a version of the principle of charity. He claims that a «good theory of interpretation» must

\footnotetext{
${ }^{11}$ I this paper I focalized the theme of perception in Quine for what concerns the problem of the other minds. For a more detailed treatment of Quine's theory of perception of external world see Zanet (2009).
} 
«optimize» agreement, from the interpreter point of view, between the interpreter and the subject of interpretation. For «it cannot be correct [a theory] that makes a man assent to very many false sentences» (Davidson 1984, 169). Consequently, Davidsonian interpreter should assume the truth of a large part of the subject's beliefs.

This assumption seems to be a direct consequence of Quine's reflections on the same point according to which the "maxim of translation" underlying our understanding of logical connectives in the jungle language is inspired to the commonsense assumption that «one's interlocutor's silliness, beyond a certain point, is less likely than bad translation -or, in the domestic case, linguistic divergence» (Quine 1960: 59).

According to Davidson the entire theory of interpretation «is built on the norms of rationality». When the interpreter applies the theory to «actual agents» he «assigns his own sentences to capture the contents of another's thoughts and utterances». This «process necessarily involves deciding which pattern of assignments makes the other intelligible (not intelligent, of course!), and this is a matter of using one's own standards of rationality to calibrate the thoughts of the other» (Davidson 2004: 129-30). What are the norms we follow in ascribing attitudes? Davidson suggests that «the semantic contents of attitudes and beliefs determine their relations to one another and to the world in ways that meet at least rough standards of consistency and correctness» (Davidson 2004: 114).

According to Davidson we project our own standards of rationality on the target of our interpretation. This seems to be a consequence of the radical interpretation approach: if we don't have any previous knowledge of the subject's language, desires, belief, then we can do nothing but projecting our structure of norms. But even if we concede that we can make a clear sense of what kind of rationality standards we employ, one question is left open: is this the correct picture of projection?

Quine expresses some perplexities about Davidson's picture when he writes that in translation what we want to maximize is «not truth or agreement with us on the part of the native, but psychological plausibility according to our intuitive folk-psychology». And «the folk-psychology involved is very much a matter of empathy». (Quine 1990: 158). We should be ready to attribute animism, in Quine's example, to the jungle people even if that belief is not true or not rational according to our standards. Quine writes: 
The translator will depend early and late on psychological conjectures as to what the native is likely to believe. This policy already governed his translations of observation sentences. It will continue to operate beyond the observational level, deterring him from translating a native assertion into too glaring a falsehood. He will favor translations that ascribe belief to the native that stand to reason or are consonant with the native's observed way of life. (Quine 1992: 46)

The linguist will rely also on observation of the local folkways. The child does too, but the linguist is a more seasoned observer. Unlike the child, the linguist will not accept everything the native says as true. He will indeed assume sincerity, barring evidence to the contrary, but he will try as an amateur psychologist to fit his interpretations of the native sentences to the native's likely belief rather than to the facts of circumambient nature. Usually the outcome will be the same, since people are so much alike; but his observation of the folkways is his faltering guide to the divergences. (Quine 1995: 80)

The passages above are pretty clear about the policy that the interpreter should follow. He should ascribe belief that "stand to reason" for the native, are "consonant" with the native way of life. His interpretation must respond to what is likely for the native to believe in consideration of the native's folkways. Trying to fit the interpretation of native's belief to his behavior in his natural environment, in his ecological niche in Dennett's phrase (Dennett 1987: 49), can give good results since we assume that people are alike. But when divergences emerge the interpreter's guide is, again, the observation of the native and his people way of life.

It seems that Quine is pointing out a tension between the method of truth (or whatever normative notion can play such a role as, for example, rational agreement) and the method of psychological plausibility. The former seems to appeal to normative standards predetermined by the interpreter. The latter does not seem to appeal to predetermined normative standards: we can say, in a first approximation, that the standards are negotiated with the contribute of empathetic projection. The crucial consequences that seem to me right to take from this is that Quinean interpreter does not deny that some normative standards play a role in belief's attribution. He thinks that the legitimate question is not just what are the standards we employ or should employ in interpretation but we may legitimately ask for the standards of who we employ. This is strictly connected to more 
general questions. What we are interested in when we try to understand people, when we exercise mindreading? How much logicality or illogicality, consistence or inconsistence, coherence or incoherence, are we disposed to attribute to the interlocutor?

In every day cases we are often really good at recognizing a certain degree of coherence even in wrong reasoning, or in false ones. If what matters is understanding, what we need is not just reveal and impute an error to our interlocutor. What we need is to be 'able' to follow 'her' flux of reasoning or 'her' chain of actions. Like as in Quine's example of animist culture, what matters is not that something may appear to us as totally irrational for it could be perfectly consequent for our interlocutor. And we do not need to speculate a lot about jungle people case because adult people who try to make sense of children's behavior and beliefs are often facing the same kind of situation. If I want to have any chance to understand my son or my daughter when they play or ask me something, I have to follow his or her chain of reasoning and acting even if they are guided by standards quite different from mine adult ones.

From this point of view, the Quinean inspired hybrid theory based on empathy does not exclude the use of normative notions and the appeal to rationality. It asks to shift the centre of the evaluations from me to you, from us to them. How much we are inclined to do this in everyday dealings can be the subject for further valuable psychological research and philosophical analysis. A further point I can envisage is that the shift can have a noteworthy ethical value for it suggests the way for a full blown and wholehearted comprehension of the others, even if it asks for a downsizing of the ideal of reason and rationality as universal.

Giancarlo Zanet University of Palermo Department of Philosophy 90128 - Palermo, Italy gzanet@alice.it

\section{References}

Baron- Cohen, Simon. 1995. Mindblindness: An Essay on Autism and Theory of Mind. Cambridge, MA: MIT Press. 
Blackmore, Susan \& Frith, Uta. 2003. How does the brain deal with the social world? NeuroReport: 14 (18): 1-9.

Churchland, Paul M. 1979. Scientific Realism and the Plasticity of Mind. New York: Press Syndicate of the University of Cambridge.

Currie, Gregory \& Ravenscroft, Ian. 2002. Recreative Minds. Oxford: Oxford University Press.

Davidson, Donald. 1984. Inquiries into Truth and Interpretation. Oxford: Clarendon Press.

Davidson, Donald. 2004. Problems of Rationality. Oxford: Clarendon Press.

Dennett, Daniel C. 1987. Intentional Stance. Cambridge, MA - London: MIT Press.

Elian, Naomi, Hoerl, Cristoph, McCormack, Teresa \& Roesseler, Johannes (eds.). 2005. Joint Attention: Communication and other minds. Oxford: Oxford University Press.

Fodor, Jerry 1987. Psychosemantics. Cambridge, MA: MIT Press.

Gallese, Vittorio. 2001. The "shared manifold" hypothesis: From mirror neurons to empathy. Journal of Consciousness Studies 8 (5-7): 33-50.

Gallese, Vittorio, Keysers, Christian \& Rizzolatti, Giacomo. 2004. A unifying view of the basis of social cognition. Trends in Cognitive Sciences 8: 396-403.

Goldman, Alvin I. 1989. Interpretation Psychologized. Mind and Language 4 (3): 161-185

Goldman, Alvin I. 2006. Simulating Minds: The Philosophy, Psychology, and Neuroscience of Mindreading. Oxford: Oxford University Press.

Goldman, Alvin I. 2009. Mirroring, mindreading and simulation. In Mirror Neuron Systems: The Role of Mirroring Processes In Social Cognition, edited by J. Pineda. New York: Humana Press.

Gopnik, Allison \& Meltzoff, Andrew. 1997. Words, Thoughts and Theories. Cambridge, MA: MIT Press.

Gopnik, Allison, Meltzoff, Andrew \& Kuhl, Patricia. 1999. The Scientist in the Crib. New York: HarperCollins.

Gordon, Robert M. 1986. Folk Psychology as Simulation. Mind and Language 1: 158-171.

Gordon, Robert M. 1995. Simulation Without Introspection or Inference from Me to You. In Mental Simulation, edited by M. Davies and T. Stone. London: Blackwell.

Gordon, Robert M. 2005. Intentional Agent Like Myself. In Perspectives on Imitation. Volume 2, edited by S. Hurley and Chater N. Cambridge, MA - London: MIT Press.

Kaheneman, Daniel, Slovic, Paul \& Tversky, Amos (eds.) 1982. Judgment Under Uncertainty: Heuristcs and Biases. Cambridge: Cambridge University Press. 
Heal, Jane. 2003. Mind, Reason and Imagination. Cambridge: Cambridge University Press.

Hurley, Susan \& Chater, Nick. (eds.). 2005. Perspective on Imitation: From Neuroscience to Social Science. Voll. 1-2. Cambridge, MA, London: The MIT Press.

Leslie, Alan. 1987. Pretence and representation: The origins of "theory of mind." Psychological Review 94: 412-426.

Leslie, Alan. 1988. Some implications of pretense for mechanisms underlying the child's theory of mind. In Developing Theories of Mind, edited by J. Astington, P. Harris and D. Olson. Cambridge: Cambridge University Press.

Leslie, Alan. 1994. Pretending and believing: Issues in the theory of ToMM. Cognition 50: 211-238.

Meltzoff, Andrew \& Moore, Keith. 1977. Imitation of Facial and Manual Gestures by Human Neonates, Science198: 75-78.

Meltzoff, Andrew. 2009. Roots of Social Cognition: The Like-me Framework. In Minnesota Symposia on Child Psychology. Meeting The Challenge of Translational Research in Child Psychology, edited by D. Cicchetti and M.R. Gunnar. New York: Wiley

Nichols, Shaun \& Stich, Stephen P. 2003. Mindreading. Oxford: Oxford University Press.

Quine, Willard Van Orman. 1960. Word and Object. Cambridge, MA: The MIT Press.

Quine, Willard Van Orman. 1989. Mind, Brain and Behavior. In Confession of a Confirmed Extensionalist and Other Essays, edited by D. Føllesdal and D.B. Quine. Cambridge, MA - London: Harvard University Press, 2008.

Quine, Willard Van Orman. 1953. The Problem of Meaning in Linguistics. In From a Logical Point of View. Cambridge MA - London: Harvard University Press, 1980.

Quine, Willard Van Orman. 1990. Reply to Gilbert Harmann. In Perspectives on Quine, edited by R.B. Barrett and R.F. Gibson. Oxford: Blackwell.

Quine, Willard Van Orman. 1992. Pursuit of Truth. Cambridge, MA - London: Harvard University Press.

Quine, Willard Van Orman. 1995. From Stimulus To Science. Cambridge, MA London: Harvard University Press.

Taghard, Paul \& Nisbett, Richard E. 1983. Rationality and Charity. Philosophy of Science 50: 250-267.

Rainone, Antonio. 2005. La riscoperta dell'empatia. Attribuzioni intenzionali e comprensione nella filosofia analitica. Napoli: Bibliopolis 2005.

Rainone, Antonio. 2010. Quine. Roma: Carocci.

Stich, Stephen P. 1983. From Folk Psychology to Cognitive Science. Cambridge, MA: The MIT Press.

Stich, Stephen P. 1985. Could Man Be An Irrational Animal? Synthese 64: 115-135. 
Stich, Stephen P. 1990. The Fragmentation of Reason: Preface to a Pragmatic Theory of Cognitive Evaluation. Cambridge, MA: The MIT Press.

Stich, Stephen P. \& Nichols, Shaun. 2003. Folk-Psychology. In The Blackwell Guide to Philosophy of Mind, edited by S.P. Stich and T.A. Warfield. Oxford: Blackwell.

Tomasello, Michael. 1999. The Cultural Origins of Human Cognition. Cambridge, MA - London: Harvard University Press.

Zanet, Giancarlo. 2005. Le radici del naturalismo. Macerata: Quodlibet.

Zanet, Giancarlo. 2009. Naturalizzazione, mente e conoscenza. In W.V. Quine, edited by Renato Pettoello e Paolo Valore. Milano: Franco Angeli. 